\title{
Nutritional status survey of children with autism and typically developing children aged 4-6 years in Heilongjiang Province, China
}

\author{
Caihong Sun ${ }^{1,2}$, Wei Xia ${ }^{2}$, Yan Zhao ${ }^{3}$, Nannan $\mathrm{Li}^{1,3}$, Dong $\mathrm{Zhao}^{3}$ and Lijie Wu ${ }^{1} *$ \\ ${ }^{1}$ Department of Children Health and Hygiene, School of Public Health, Harbin Medical University, Harbin, People's Republic of China \\ ${ }^{2}$ Children Development and Behavior Research Center, Harbin Medical University, Harbin, People's Republic of China \\ ${ }^{3}$ Department of Nutrition and Food Hygiene, School of Public Health, Harbin Medical University, Harbin, People's Republic of China
}

(Received 4 August 2012 - Final revision received 14 February 2013 - Accepted 18 February 2013)

Journal of Nutritional Science (2013), vol. 2, e16, page 1 of 8

doi:10.1017/jns.2013.9

\section{Abstract}

Autism is a neurodevelopmental disability that may affect nutritional management of children with autism. This study aimed to compare the nutritional status of children with autism with that of typically developing children (aged 4-6 years) in China. Nutritional status was assessed by means of nutritional data, anthropometric data, biochemical assessment, physical examination for nutrient deficiencies and providing a questionnaire to parents. A total of fiftythree children with autism and fifty-three typically developing children were enrolled in this study. The parents were asked to complete the questionnaire regarding the eating behaviour and gastrointestinal symptoms of their children. They were also asked to provide a $3 \mathrm{~d}$ food diary. Children with autism exhibited several abnormalities in terms of eating behaviour and gastrointestinal symptoms. The levels of vitamins $\mathrm{A}$ and $\mathrm{B}_{6}, \mathrm{Zn}$ and $\mathrm{Ca}$ intakes were $<80 \%$ of the dietary reference intakes in both groups. In addition, the proportions of vitamin $\mathrm{C}$ and $\mathrm{Ca}$ intake deficiencies in the autism group were significantly higher than those in the control group. Serum $\mathrm{Zn}$ level was less than the normal reference range in both the groups. Serum Ca, vitamin $\mathrm{A}$ and folate levels in children with autism were significantly lower when compared with children without autism. According to the anthropometric data, the mean BMI, weight-for-height $Z$-score $\left(Z_{\mathrm{WH}}\right)$ and $\mathrm{BMI}$ for age $Z$-score $\left(Z_{\mathrm{BMIA}}\right)$ of children with autism were significantly higher than those of the typically developing children. Thus, nutritional inadequacies were observed in children with autism and typically developing children in China, which were, however, more pronounced among children with autism.

Key words: Children with autism: Eating behaviour: Nutrient intake: Biochemical assessment: Anthropometry

Autism is a neurodevelopmental disability that is characterised by deficiencies in social reciprocity and language skills that are associated with repetitive behaviours and restricted interests ${ }^{(1)}$. The incidence of autism has rapidly increased since the 1970 s. According to reports, the prevalence rates are approximately 4.1 cases per 1000 children in Australia ${ }^{(2)}$ and 6.5 cases per 1000 children in Canada $^{(3)}$, which are consistent with the prevalence estimates from the USA and the UK for several years $^{(4-7)}$. Although nationwide epidemiological data on children with autism are not available in China, several regional studies have suggested that the prevalence of autism is
$1 \cdot 1-2 \cdot 3$ per 1000 children $^{(8-11)}$. Children with autism are frequently observed to have peculiar eating habits that result from the connatural disease characteristics ${ }^{(12)}$. Although studies on nutrient intake of children with autism have shown conflicting results ${ }^{(13-15)}$, most studies have reported that the dietary intake of children with autism is less than the recommended amounts of some minerals and vitamins ${ }^{(16,17)}$. They may also select fewer food categories ${ }^{(18)}$, which may jeopardise their nutritional status, compared with that in children without autism ${ }^{(13)}$. Moreover, a high prevalence of gastrointestinal ailments may aggravate the digestive

Abbreviation: DRI, dietary reference intake.

* Corresponding authors: W. Xia, fax +864518750 2885, email xiawei1023@126.com; L. Wu, fax +8645187502867, email lijiewu64@126.com 
and absorption functions among children with autism ${ }^{(19,20)}$. The interaction between different genetic backgrounds and nutrients may also result in different metabolic models and utility levels of nutrients, regardless of the same quantity and quality of food intake ${ }^{(21,22)}$. Therefore, appraisal of the nutritional status of children with autism should not be based solely on their dietary intake.

In Heilongjiang Province, located in the northeast region of China, the economic condition is not as thriving as that in the southern part of the country. Thus, malnutrition in the children in this area is more common, for example vitamin $A$, $\mathrm{Ca}$ and $\mathrm{Zn}$ deficiencies ${ }^{(23)}$. In the present study, we hypothesised that children with autism in this area have inadequate nutrient intake and lower serum micronutrient level than children who underwent normal developmental stages based on a cross-sectional case-control study. We also assessed whether or not the poor nutritional state is associated with anthropometric data and clinical symptoms of nutrient deficiencies, given that these factors may have important implications in nutritional management of children with autism.

\section{Materials and methods}

\section{Participants}

A total of fifty-three children with autism (forty-five boys and eight girls; aged 4-6 years) who visited the Children Development and Behavior Research Center of Harbin Medical University (Harbin, China) from November 2009 to June 2011 were included in this study. Diagnosis was based on the criteria for autism defined in the Diagnostic and Statistical Manual of Mental Disorders, Fourth Edition (DSM-IV) as well as on a childhood autism rating scale score of thirty according to a diagnostic interview conducted by a developmental paediatrician. The exclusion criteria included Asperger's disorder, pervasive developmental disorder, chronic seizures and recent infection as well as the use of any nutritional supplements. The study also recruited fiftythree children considered to be typically developing children from nursery schools around the Harbin Medical University. These participants were typically developing children who, according to their parents, had not experienced delays in motor and language development or behavioural problems. These children matched the age bracket (within 4 months), sex, occupations of parents and family economic status of the enrolled children with autism. All of the participants were of Han ethnicity.

This study was conducted according to the guidelines stated in the Declaration of Helsinki. All the procedures that involved human subjects were approved by the Research and Ethics Committee of Harbin Medical University. Written informed consent was obtained from the parents of each participant prior to enrolment.

\section{General condition survey}

The parents of the children with and without autism completed the questionnaire in which information regarding the children's eating behaviour, gastrointestinal symptoms and general condition was obtained. Before the survey was conducted, we calculated Cronbach's $\alpha$ coefficients to estimate the reliability of the reported factors in the questionnaire ( $\alpha$ coefficients $>0 \cdot 70$ ).

The questionnaire survey was conducted through face-to-face interviews between the investigators and the parents of both groups. The following data were obtained from the questionnaire: name, age, date of birth, birth condition, eating habits (such as food selectiveness (fastidious about their food), resisting trying new foods (refusing to eat those foods not tried before), eating independence and attention (the eating time for a meal is more than $30 \mathrm{~min})$ ), gastrointestinal ailments (such as abdominal pain (gastrospasm or enterospasm), constipation (reduced defecation frequency, decreased faeces, dry stool, need great effort to defecate), chronic diarrhoea (increased defecation frequency and loose stools for more than 2 months), excessive flatulence (often hiccup or pass gas) and disgorging), sleep status, food or drug allergies, self-injurious behaviour, tantrums, aggression, oppositional behaviour, family information, etc.

\section{Dietary assessment}

The parents of each subject were requested to provide a $3 \mathrm{~d}$ food diary of their children for two weekdays and one weekend (covering the consumption over $24 \mathrm{~h}$ on each of the $3 \mathrm{~d}$ ). A picture booklet that includes local consumed food types, food pictures, the proportion of a serving and the estimated weight was handed out to the parents of each participant so that they could qualitatively and quantitatively describe all types of food consumed by their children and estimate the food intake.

A registered dietitian analysed the $3 \mathrm{~d}$ diet diaries by using the nutrient calculator software (Fei Hua V2.3, The Institute for Nutrition and Food Security, Chinese Center for Disease Control and Prevention). The study used the dietary reference intakes (DRI), including the recommended nutrient intakes and the adequate intakes recommended by the Chinese Nutrition Academy (2000), as norms for individual intake ${ }^{(24)}$. Results were converted to recommended nutrient intakes or adequate intakes percentages for energies and various nutrients per day based on DRI with respect to the age group. In this study, 'sufficient intake' is defined as $\geq 100 \%$ of the DRI, 'borderline intake' corresponds to $80-99 \%$ of the DRI and 'inadequate intake' indicates $<80 \%$ of the DRI.

\section{Detection of the biochemical index for nutritional levels}

Fasted blood samples $(5 \mathrm{ml})$ were obtained from the participants through venipuncture. Approximately $1 \mathrm{ml}$ of blood was collected and placed into an EDTA-coated tube for $\mathrm{Hb}$ determination ( $\mathrm{Hb}$ automatic blood cell analyser, Sysmex Corporation). The remaining blood was centrifuged. $\mathrm{Fe}, \mathrm{Zn}$ and $\mathrm{Ca}$ in the serum were separated by flame atomic absorption spectroscopy (AA6300 C atomic absorption spectrophotometer, Shimadzu) at $248.3,213.9$ and $422.7 \mathrm{~nm}$, respectively, by using various hollow cathode lamps 
(Perkin-Elmer). Vitamin A was determined with the HPLC technique according to Miller's method ${ }^{(25)}$ (Waters 2960 Instrument). Vitamin $\mathrm{B}_{12}$ and folic acid levels were assessed by using a commercial RIA kit (Navy Gen Hospital), in which vitamin $\mathrm{B}_{12}$ and folic acid were labelled with radioactive ${ }^{57} \mathrm{Co}$ and ${ }^{125} \mathrm{I}$. The values were determined using an automatic GC 911 gamma counter system (USTC Development Corporation).

\section{Physical examinations for malnutrition (undernutrition)}

Physical examinations were conducted by trained paediatricians. The examined parts of the body, symptoms and potential underlying nutrient deficiencies are listed in Table 1.

\section{Anthropometric data}

All of the required gauger trainings were completed before the measurement was carried out. Anthropometric data were collected using an HCS-200-RT weightometer and an HGM-200 wall anthropometer (Haerbin Biomedical Company). The accuracy of both instruments was confirmed before use: accuracies for body weight and stature were $\pm 0 \cdot 1 \mathrm{~kg}$ and $\pm 0.1 \mathrm{~cm}$, respectively. The children were examined with light clothing and bare feet. Height and weight values were obtained twice and the averages of height and weight for each child were obtained.

The evaluation of the development status was completed using the standardised WHO procedures ${ }^{(26)}$. The height for age, weight for age, BMI for age and weight for height (age $<60$ months) $Z$-scores $\left(Z_{\mathrm{HA}}, Z_{\mathrm{WA}}, Z_{\mathrm{BMIA}}\right.$ and $Z_{\mathrm{WH}}$, respectively) were calculated using the WHO Child Growth Standard (WHO Anthro software, version 3.01) ${ }^{(27)}$. These growth indicators were interpreted according to the Training Course on Child Growth Assessment (Geneva, WHO) ${ }^{(28)}$.

\section{Data analysis}

The data on the general condition questionnaire were encoded in a computer by using EpiData V 3.02 software (Chinese Center for Disease Control and Prevention). The study used the Fei Hua (V2.3) nutrient calculator to compute energy and various nutrient intakes per day based on the data from the dietary questionnaire. The $\chi^{2}$ test, two-sample/group $t$ test and Fisher's exact test were used to determine the significance level. The Monte Carlo exact test was also used to evaluate the growth problem distribution of the children in both autism and control groups. $P$ values $<0.05$ were considered statistically significant.

\section{Results}

\section{Participant characteristics}

The mean ages of the fifty-three children with autism and fiftythree typically developing children were $59 \cdot 3$ (SD 7.4) (50-78 months) and 59.4 (SD 7.5) (50-79 months) months, respectively. The parents of the children with autism were more likely to report the eating problems of their children (e.g. selectiveness, resisting trying new foods and inability to focus and eat independently compared with the parents of the typically developing children) $(P<0 \cdot 01$; Table 2$)$. Children with autism experienced constipation and chronic diarrhoea to a higher extent and had a family history of allergies or immune diseases $(P<0 \cdot 001)$. A higher number of children with autism also exhibited food or drug allergies, self-injurious behaviour, tantrums and aggressive or oppositional behaviour compared with the typically developing children $(P<0 \cdot 01)$. No significant differences were observed in other gastrointestinal symptoms and sleep status between the two groups.

\section{Dietary intake}

Table 3 summarises the average intake of various nutrients per day of children with autism and those with typical development after the $3 \mathrm{~d}$ diet diaries were analysed. Inadequate vitamin $\mathrm{A}$, vitamin $\mathrm{B}_{6}, \mathrm{Ca}$ and $\mathrm{Zn}$ intakes were generally observed in both groups. The mean vitamin $\mathrm{C}$ intake was also inadequate for children with autism except for the previously mentioned nutrients. The mean dietary vitamin $\mathrm{E}$, niacin, $\mathrm{Mg}$ and $\mathrm{Fe}$ intakes were sufficient, whereas the mean dietary vitamin $\mathrm{B}_{1}$, vitamin $\mathrm{B}_{2}$ and folic acid intakes were at the borderline for both groups. The numbers of typically developing children with inadequate dietary vitamin $\mathrm{C}$ and $\mathrm{Ca}$ intakes were significantly less than those of children with autism $(P<0 \cdot 05)$. No statistical differences were found between autism and normally developing groups in terms of the number of children who had sufficient or borderline intakes of other nutrients.

Also, no statistically significant difference in the mean protein, carbohydrates and fat intakes was observed between the two groups. However, the mean contribution of energy

Table 1. Part of the body examined, symptoms and nutrient deficiencies

\begin{tabular}{lll}
\hline Body part/system & & \multicolumn{1}{c}{ Clinical symptoms } \\
\hline Whole body & Emaciation, anasarca, anaemia & Potential nutrient deficiency \\
Skin & Dryness, roughness, petechia, seborrheicdermatitis, pellagra & Protein, Fe \\
Hair & Scarcity, dryness, brittleness & Vitamin A, vitamin C, vitamin B, niacin \\
Eyes & Bitot's spot, corneal drying, pale conjunctiva & Protein, Zn, Fe \\
Lips & Angular chilitis, cheilitis & Vitamin A, Fe \\
Oral & Gingiva bleeding, scarlet geographical tongue, glossitis & Vitamin C, niacin, vitamin B $B_{2}$ \\
Nails & Scaphoid, unfairness & Fe, Zn \\
Skeleton & Squared skull, rib eversion, pectus carinatum, rachitic rosary, O- or X-shaped legs & Vitamin D, Ca \\
Nervous system & Muscle weakness, tingling sensation & Vitamin B \\
\hline
\end{tabular}


Table 2. Comparison of the general condition, eating behaviour, gastrointestinal symptoms, sleep status, agnostic behaviour and family history between children with autism and typically developing children ( $n$ 53)

(Number and percentage)

\begin{tabular}{|c|c|c|c|c|c|}
\hline \multirow[b]{2}{*}{ General condition and symptoms } & \multicolumn{2}{|c|}{$\begin{array}{l}\text { Children with } \\
\text { autism }\end{array}$} & \multicolumn{2}{|c|}{$\begin{array}{l}\text { Typically developing } \\
\text { children }\end{array}$} & \multirow[b]{2}{*}{$P^{*}$} \\
\hline & $n$ & $\%$ & $n$ & $\%$ & \\
\hline \multicolumn{6}{|l|}{ Sex } \\
\hline Male & 45 & 84.9 & 45 & 84.9 & \multirow[t]{2}{*}{1.000} \\
\hline Female & 8 & $15 \cdot 1$ & 8 & $15 \cdot 1$ & \\
\hline \multicolumn{6}{|l|}{ Age years } \\
\hline 4 & 31 & 58.5 & 31 & 58.5 & \multirow[t]{3}{*}{1.000} \\
\hline 5 & 18 & $34 \cdot 0$ & 18 & 34.0 & \\
\hline 6 & 4 & 7.5 & 4 & 7.5 & \\
\hline \multicolumn{6}{|l|}{ Occupation of mother } \\
\hline Intellectual work & 36 & 67.9 & 40 & 75.5 & \multirow[t]{2}{*}{0.388} \\
\hline Physical work & 17 & $32 \cdot 1$ & 13 & 24.5 & \\
\hline \multicolumn{6}{|l|}{ Occupation of father } \\
\hline Intellectual work & 37 & $69 \cdot 8$ & 38 & $71 \cdot 1$ & \multirow[t]{2}{*}{0.831} \\
\hline Physical work & 16 & $30 \cdot 2$ & 15 & $28 \cdot 3$ & \\
\hline \multicolumn{6}{|l|}{ Family income per capita per month } \\
\hline$\geq 3000$ Chinese Yuan & 27 & $50 \cdot 9$ & 23 & $43 \cdot 3$ & \multirow[t]{2}{*}{0.436} \\
\hline$<3000$ Chinese Yuan & 26 & $49 \cdot 1$ & 30 & $56 \cdot 6$ & \\
\hline Food selectiveness & 23 & 43.4 & 9 & $17 \cdot 0$ & 0.003 \\
\hline Resists trying new foods & 33 & $62 \cdot 3$ & 15 & $28 \cdot 3$ & $<0.001$ \\
\hline Bad eating independence and attention & 33 & $62 \cdot 3$ & 3 & 5.7 & $<0.0001$ \\
\hline Abdominal pain & 11 & $20 \cdot 8$ & 2 & 3.8 & 0.008 \\
\hline Constipation & 21 & 39.6 & 3 & 5.7 & $<0.0001$ \\
\hline Chronic diarrhoea & 14 & $26 \cdot 4$ & 0 & 0 & $<0.0001$ \\
\hline Excessive flatulence & 10 & $18 \cdot 9$ & 4 & 7.5 & 0.085 \\
\hline Disgorging & 5 & 9.4 & 1 & 1.9 & 0.207 \\
\hline Sleep disturbance & 11 & $20 \cdot 8$ & 4 & 7.5 & 0.051 \\
\hline Food or drug allergy & 15 & $28 \cdot 3$ & 4 & 7.5 & 0.005 \\
\hline Self-injurious behaviour, tantrums, aggression, oppositional behaviour & 20 & 37.7 & 6 & 11.3 & 0.002 \\
\hline Family history of allergy or immunity to diseases & 28 & $52 \cdot 8$ & 10 & $18 \cdot 9$ & $<0.0001$ \\
\hline Father/mother with a moderate or severe gastrointestinal problem & 23 & 43.4 & 18 & $34 \cdot 0$ & 0.319 \\
\hline
\end{tabular}

${ }^{*} \chi^{2}$ test.

intake from dietary fat $(27.2 \%)$ in children with autism was lower than the recommended percentage distribution (30-35 $\%$ for children aged 4-6 years).

\section{Biochemical determination for nutritional levels}

Table 4 shows the results of the biochemical determination for nutritional levels. No significant difference was observed in the $\mathrm{Hb}$ contents between children with and without autism. Also, no statistical differences were found in the mean $\mathrm{Zn}$ and $\mathrm{Fe}$ levels between the two groups, but the mean serum Ca level in children with autism was significantly lower than that in typically developing children $(P<0 \cdot 01)$. It is clinically noteworthy that the mean serum $\mathrm{Ca}$ level in the autism group and the serum $\mathrm{Zn}$ levels in both groups were lower than the reference range. In addition, the mean serum vitamin $A$ and folic acid levels, not the vitamin $\mathrm{B}_{12}$ level, in children with autism were significantly lower than those in typically developing children $(P<$ $0 \cdot 01$ and $P<0.05$, respectively). All of the three detected vitamins were within the reference ranges in both groups.

\section{Physical examinations for malnutrition}

Physical examinations were conducted to assess the nutritional status of both groups. No significant differences were observed in the clinical symptoms between the groups.
Among the fifty-three children with autism, one child had pale conjunctiva, six had scarce, dry and brittle hair, three had dry skin, one had cheilitis and three had rib eversion (Table 5). Among the typically developing children, four subjects had scarce, dry and brittle hair, two had dry skin, one had non-smooth nails and two had rib eversion. No other symptoms for malnutrition were found among the participants.

\section{Anthropometry}

Table 6 summarises the average body height, body weight and general nutritional condition ( $Z$ score) of the fifty-three children with autism and fifty-three typically developing children. No statistical differences in height and weight were observed between the two groups. The mean BMI and the mean $Z_{\text {BMIA }}$ in children with autism were significantly higher than those in typically developing children $(P<0 \cdot 05)$. No statistical differences in the mean $Z_{\mathrm{WA}}$ and $Z_{\mathrm{HA}}$ between the two groups were observed. However, the mean $Z_{\mathrm{WH}}$ for children aged $<60$ months in the autism group was significantly higher than that in the typically developing children $(P<0 \cdot 05)$.

\section{Discussion}

This cross-sectional study compared the nutritional status of children with autism with that of typically developing children 


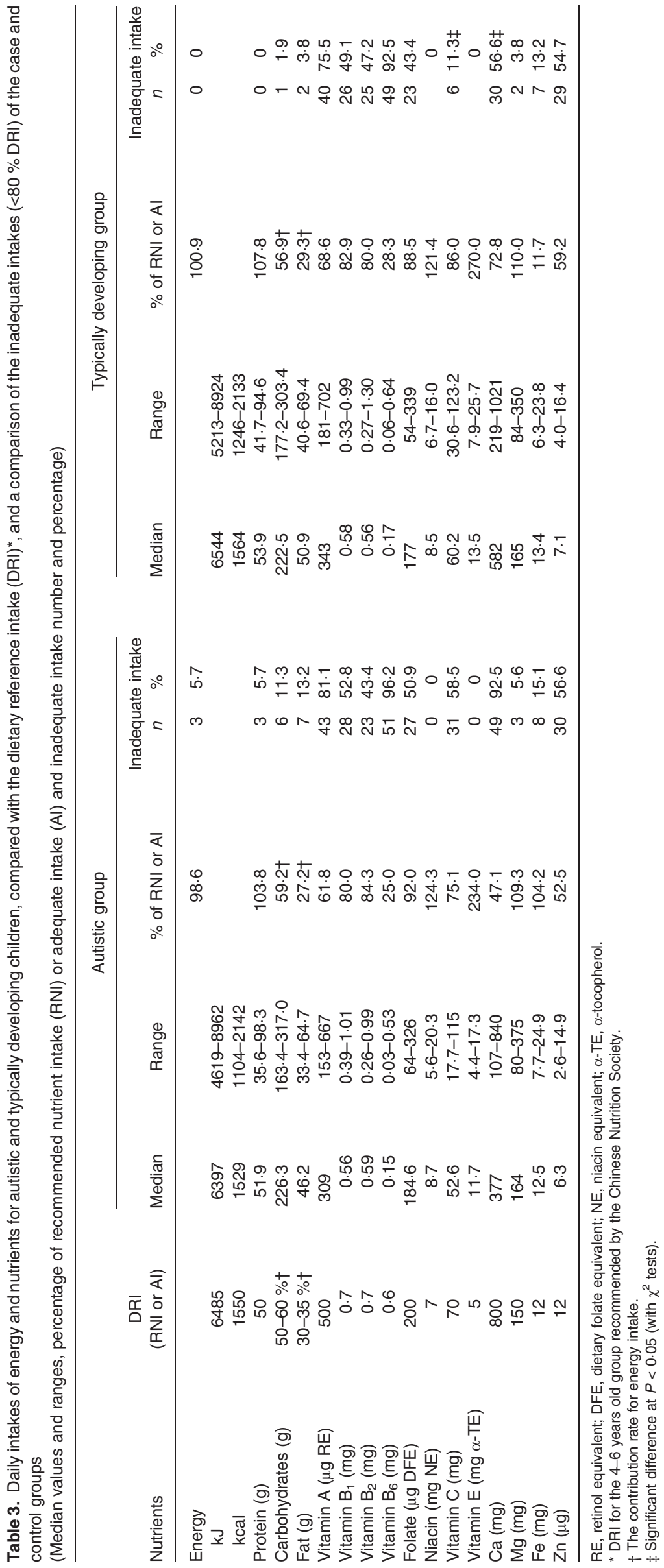


Table 4. Comparison of the biochemical nutritional levels of autistic and normally developing children ( $n$ 53) (Mean values and standard deviations)

\begin{tabular}{|c|c|c|c|c|c|c|}
\hline \multirow[b]{2}{*}{ Item } & \multirow[b]{2}{*}{ Reference range } & \multicolumn{2}{|c|}{ Autism group } & \multicolumn{2}{|c|}{ Normally developing group } & \multirow[b]{2}{*}{$P^{\star}$} \\
\hline & & Mean & SD & Mean & SD & \\
\hline $\mathrm{Hb}(\mathrm{g} / \mathrm{l})$ & $>120$ & 123 & $6 \cdot 1$ & 123 & $6 \cdot 7$ & 0.740 \\
\hline $\mathrm{Zn}(\mu \mathrm{mol} / \mathrm{l})$ & $76 \cdot 5-140 \cdot 0$ & $72 \cdot 9$ & $8 \cdot 2$ & 73.5 & $15 \cdot 0$ & 0.790 \\
\hline $\mathrm{Ca}(\mathrm{mmol} / \mathrm{l})$ & $1.55-2.10$ & 1.54 & 0.04 & 1.59 & 0.12 & 0.007 \\
\hline $\mathrm{Fe}(\mathrm{mmol} / \mathrm{l})$ & $7.52-11.82$ & $8 \cdot 17$ & 0.59 & 7.98 & 0.91 & 0.218 \\
\hline Vitamin A ( $\mu \mathrm{g} / \mathrm{dl})$ & $25-56$ & 28 & 5.9 & 41 & $7 \cdot 8$ & $<0.0001$ \\
\hline Folate $(\mathrm{nmol} / \mathrm{l})$ & $5 \cdot 31-39 \cdot 86$ & $24 \cdot 32$ & $10 \cdot 86$ & $29 \cdot 13$ & 10.95 & 0.025 \\
\hline Vitamin $B_{12}(p m o l / l)$ & $139 \cdot 86-653 \cdot 42$ & $464 \cdot 47$ & $192 \cdot 18$ & $556 \cdot 13$ & $328 \cdot 78$ & 0.083 \\
\hline
\end{tabular}

* Two-sample/group $t$ test.

in China. An inadequate nutritional status was observed in children with and without autism. Children with autism exhibited more abnormalities in terms of eating behaviour and gastrointestinal symptoms, higher proportions of vitamin $\mathrm{C}$ and $\mathrm{Ca}$ intake inadequacies, as well as lower levels of serum $\mathrm{Ca}$, vitamin $A$ and folate. According to the anthropometry data, higher mean BMI, $Z_{\mathrm{WH}}$ and $Z_{\mathrm{BMIA}}$ were observed in children with autism than in typically developing children.

Eating problems are more frequent in children with autism than in typically developing children. This finding agrees with that in several previous reports, in which children with autism have higher incidence of food refusal and limited food repertoire than typically developing children ${ }^{(15,18)}$. Strict adherence to rituals and routines, which is a core feature of autism, has been suggested as a possible explanation for these eating problems ${ }^{(12)}$. Sensory integration dysfunction and sensory sensitivity that can cause eating discomfort also contribute to the food selectiveness of a child with autism ${ }^{(29)}$. Such behaviours as food selectiveness and resisting trying new foods may indicate an attempt to compensate for this discomfort ${ }^{(30)}$. Parents of children with autism often report a high rate of gastrointestinal symptoms ${ }^{(31,32)}$ despite the lack of medical causes. Similar results were also found in the present study. Levy et al. ${ }^{(33)}$ reported that some gastrointestinal symptoms may be the result of opioid peptides that are formed from the incomplete breakdown of foods that contain gluten and casein. However, several studies have shown that a gluten-free, casein-free diet does not significantly alter the symptoms in children with

Table 5. Physical examination for malnutrition in children with autism and typically developing children $(n 53)$

\begin{tabular}{|c|c|c|c|c|c|}
\hline \multirow[b]{2}{*}{ Symptoms } & \multicolumn{2}{|c|}{$\begin{array}{l}\text { Autistic } \\
\text { group }\end{array}$} & \multicolumn{2}{|c|}{$\begin{array}{c}\text { Typically } \\
\text { developing group }\end{array}$} & \multirow[b]{2}{*}{$P^{*}$} \\
\hline & $n$ & $\%^{*}$ & $n$ & $\%$ & \\
\hline Pale conjunctiva & 1 & 1.9 & 0 & 0.0 & 1.000 \\
\hline Scare, dry and brittle hair & 6 & 11.3 & 4 & 7.5 & 0.506 \\
\hline Dry skin & 3 & $5 \cdot 7$ & 2 & 3.8 & 0.647 \\
\hline Cheilitis & 1 & 1.9 & 0 & 0.0 & 1.000 \\
\hline Non-smooth nails & 0 & 0.0 & 1 & 1.9 & 1.000 \\
\hline Rib eversion† & 3 & 5.7 & 2 & $3 \cdot 8$ & 0.647 \\
\hline
\end{tabular}

${ }^{*}$ Fisher's exact test.

† Rib eversion: the bottom two ribs are prominent over the periphery of bony thorax. autism $^{(34)}$. Commercial gluten-free, casein-free products are not yet available in China and the dietary intakes of children with autism in our study were not restricted. Hence, the mechanism by which gastrointestinal problems occur in children with autism should be further investigated.

The limited number of published studies on nutrient intakes in children with autism have yielded conflicting results ${ }^{(13,14,35)}$. Our results showed that the mean dietary intakes of vitamins $\mathrm{A}$ and $\mathrm{B}_{6}, \mathrm{Ca}$ and $\mathrm{Zn}$ in children with autism and typically developing children were $<80 \%$ of the DRI. This result indicated that the intakes of these nutrients were commonly inadequate among Chinese children. Based on the 2002 National Survey of Resident Nutritional Status in China, the rates of inadequacy intake and the borderline inadequacy intake were 9.1 and $41.8 \%$ for vitamin $\mathrm{A}$, respectively; the dietary Ca intake was $238 \mathrm{mg} / \mathrm{d}$, which is only one-third of the adequate intakes in Chinese children below 6 years of age $^{(36)}$. Several studies have also found that children with autism consume significantly lower amounts of $\mathrm{Ca}$ than those without autism ${ }^{(14,37-39)}$, a trend that was also observed in the present study. Based on the detected serum biochemical assessment, serum vitamin $\mathrm{A}$ and $\mathrm{Ca}$ levels in children with autism were significantly lower compared with those in children without autism (the serum $\mathrm{Ca}$ level of children with autism was also less than the reference range), which is consistent with the findings of the dietary assessment. A previous study reported that no significant difference is observed in the serum $\mathrm{Ca}$ levels between children with and without autism, and the detected values are within the normal reference range ${ }^{(40)}$. However, the serum $\mathrm{Ca}$ level is increased when the Ca deposited in the skeleton is mobilised, thereby resolving $\mathrm{Ca}$ inadequacy. The proportion of $\mathrm{Zn}$ intake inadequacy in Chinese children is approximately $50 \%{ }^{(41)}$. In the present study, although serum $\mathrm{Zn}$ levels were less than the reference range, no statistical difference was observed between the two groups. Therefore, $\mathrm{Zn}$ deficiency may be related with the characteristics of the Chinese diet, in which cereals constitute the main staple food. Moreover, the participants of our study live in the northernmost parts of China; fruit consumption in this region is much lower and vegetables are the primary source of vitamin $\mathrm{C}$. The mean vitamin $\mathrm{C}$ intake level in children with autism was inadequate and significantly lower than that in typically developing children. This result is similar to 
Table 6. Anthropometric data and $Z$ scores of children with autism and typically developing children ( $n$ 53) (Minimum to maximum, mean values and standard deviations)

\begin{tabular}{|c|c|c|c|c|c|c|c|}
\hline & \multicolumn{3}{|c|}{ Autism group } & \multicolumn{3}{|c|}{ Typically developing group } & \multirow[b]{2}{*}{$P^{\star}$} \\
\hline & Minimum to maximum & Mean & SD & Minimum to maximum & Mean & SD & \\
\hline Age (months) & $50-78$ & $59 \cdot 3$ & 7.43 & $50-79$ & 59.4 & 7.51 & 0.948 \\
\hline Height (cm) & $95 \cdot 1-125 \cdot 2$ & $111 \cdot 2$ & 7.34 & $98 \cdot 5-124.0$ & $111 \cdot 2$ & 5.78 & 0.997 \\
\hline Weight (kg) & $13 \cdot 0-35 \cdot 4$ & $21 \cdot 2$ & 4.23 & $15 \cdot 0-33 \cdot 4$ & 19.9 & 3.61 & 0.087 \\
\hline BMI $\left(\mathrm{kg} / \mathrm{m}^{2}\right)$ & $10 \cdot 9-23 \cdot 2$ & $17 \cdot 1$ & 2.56 & $12 \cdot 9-22 \cdot 1$ & $16 \cdot 0$ & 1.78 & 0.017 \\
\hline$Z_{\mathrm{WH}}{ }^{\dagger}$ & -1.34 to 4.36 & $1 \cdot 10$ & 1.57 & -1.99 to 3.10 & 0.41 & 1.04 & 0.045 \\
\hline$Z_{W A}$ & -2.84 to 4.55 & 0.94 & 1.24 & -1.63 to 3.40 & 0.51 & 1.03 & 0.052 \\
\hline$Z_{\mathrm{HA}}$ & -2.91 to 2.54 & 0.41 & 1.22 & -1.82 to 2.07 & 0.39 & 0.85 & 0.918 \\
\hline$Z_{\text {BMIA }}$ & -4.37 to 4.44 & 1.06 & 1.67 & -2.10 to 3.62 & 0.44 & $1 \cdot 13$ & 0.028 \\
\hline
\end{tabular}

* Two-sample/group $t$ test.

† The score was used for children aged below 60 months.

a previous report that children with autism tend to refuse vegetables to a higher extent than typically developing children ${ }^{(15)}$. No differences were observed in vitamin $\mathrm{B}_{12}$ levels between children with and without autism in our study. However, the serum folate levels in children with autism significantly decreased. A recent study has reported that serum homocysteine levels significantly increase and folate and vitamin $\mathrm{B}_{12}$ levels significantly decrease in children with autism compared with those in typically developing controls ${ }^{(42)}$. Some studies have also demonstrated that children with autism exhibit impaired methylation and homocysteine metabolism ${ }^{(43,44)}$. Folate and vitamin $\mathrm{B}_{12}$ have an important function in homocysteine metabolism $^{(40)}$. Therefore, the folate defect observed in our study may lead to homocysteine accumulation in the body of children with autism.

The results of this study showed that the mean BMI, $Z_{\mathrm{WH}}$ and $Z_{\text {BMIA }}$ of children with autism were significantly higher and the minimum to maximum extent of the above-mentioned parameters were wider compared with that in children without autism. This result indicated that a few children with autism were stunted, which suggests a possibility of becoming overweight and an increased risk of the more autistic children being obese. A previous work has indicated that children with autism also have the potential to be obese in addition to nutritional inadequacy ${ }^{(45)}$. Thus, priorities for future research are identified to advance the understanding and management of overweight and obesity problems in children with autism.

Given the thorough examination of the nutritional status, this study may provide contributions to the relevant literature on the nutritional status of children with autism. The biochemical indexes, which have not been completely investigated in several studies, were considered and a stricter definition of autism that potentially decreased the heterogeneity of the children under observation was used. Several limitations, however, require adequate attention. For instance, we only considered the nutritional status of vitamin D for children based on their clinical symptoms. We did not evaluate the vitamin D intake and the serum $25-\mathrm{OH}-\mathrm{D}_{3}$ levels, which are the main limitations of this study. Another limitation of the food nutrient evaluation included the scope of the food diary, which was only observed based on a $3 \mathrm{~d}$ intake. These data may not adequately indicate the variety of a typical diet ${ }^{(46)}$. In addition, all the enrolled participants were from Heilongjiang Province, an area without a prosperous economy and with a 6 month-long winter. Thus, the results from this region may differ from those from other parts of China and from other countries.

In conclusion, nutritional inadequacies were observed in children with autism and typically developing children in China; these were, however, more pronounced among children with autism. Therefore, the nutritional status of children with autism should be regularly monitored to reduce these deficiencies by dietary means or by administering appropriate vitamin and mineral supplements.

\section{Acknowledgements}

W. X. was supported by the National Natural Science Foundation of China (no. 81072298). W. X. and L. W. were involved in designing the trial and writing the trial protocol, calculating the sample size, analysing the data and finalising the manuscript. W. X. was also involved in supervising subjects' recruitment, in data collection and in drafting the manuscript. C. S. and D. Z. were involved in diet surveys, data collection, analysing the data and revising the manuscript. Y. Z. and N. L. initiated and supervised the trial as principal investigators. All authors approved the final version of the manuscript. None of the authors had a personal or financial conflict of interest.

\section{References}

1. Eigsti IM \& Shapiro T (2003) A systems neuroscience approach to autism: biological, cognitive, and clinical perspectives. Ment Retard Dev Disabil Res Rev 9, 205-215.

2. Charles J, Harrison C \& Britt H (2011) Autism spectrum disorders. Aust Fam Physician 40, 665.

3. Fombonne E, Zakarian R, Bennett A, et al. (2006) Pervasive developmental disorders in Montreal, Quebec, Canada: prevalence and links with immunizations. Pediatrics 118, e139-e150.

4. Bertrand J, Mars A, Boyle C, et al. (2001) Prevalence of autism in a United States population: the Brick Township, New Jersey, investigation. Pediatrics 108, 1155-1161.

5. Yeargin-Allsopp M, Rice C, Karapurkar T, et al. (2003) Prevalence of autism in a US metropolitan area. JAMA 289, 49-55.

6. Williams E, Thomas K, Sidebotham H, et al. (2008) Prevalence and characteristics of autistic spectrum disorders in the ALSPAC cohort. Dev Med Child Neurol 50, 672-677. 
7. Fombonne E (2003) Epidemiological surveys of autism and other pervasive developmental disorders: an update. J Autism Dev Disord 33, 365-382.

8. Zhang X, Ji CY \& Li JS (2004) The investigation of autism in children aged 2 to 6 years old in Tianjin. Chin J Reprod Health 15, 206-208.

9. Liu J, Yang XL \& Jia MX (2007) Survey on pervasive developmental disorder in 2-6 year-old children in Beijing. Chin Ment Health J 5, 290-293.

10. Cong Y, Wei X, Cai-Hong S, et al. (2010) Survey on autistic spectrum disorder in 2 to 6 years old children in Harbin city. Chin J Child Health Care 18, 750-753.

11. Wang WH, Zhai LW \& Zheng L (2003) Epidemiological investigation of autism children of Jiangsu province. Chin J Behav Med Sci 12, 173-175.

12. Cascio CJ, Foss-Feig JH, Heacock JL, et al. (2012) Response of neural reward regions to food cues in autism spectrum disorders. J Neurodev Disord 4, 9.

13. Xia W, Zhou Y, Sun C, et al. (2010) A preliminary study on nutritional status and intake in Chinese children with autism. Eur J Pediatr 169, 1201-1206.

14. Herndon AC, DiGuiseppi C, Johnson SL, et al. (2009) Does nutritional intake differ between children with autism spectrum disorders and children with typical development? I Autism Dev Disord 39, 212-222.

15. Lockner DW, Crowe TK \& Skipper BJ (2008) Dietary intake and parents' perception of mealtime behaviors in preschool-age children with autism spectrum disorder and in typically developing children. I Am Diet Assoc 108, 1360-1363.

16. Dosman CF, Drmic IE \& Brian JA (2006) Ferritin as an indicator of suspected iron deficiency in children with autism spectrum disorder: prevalence of low serum ferritin concentration. Dev Med Child Neurol 48, 1008-1009.

17. Lindsay RL, Eugene Arnold L, Aman MG, et al. (2006) Dietary status and impact of risperidone on nutritional balance in children with autism: a pilot study. J Intellect Dev Disabil 31, 204-209.

18. Schreck KA, Williams K \& Smith AF (2004) A comparison of eating behaviors between children with and without autism. J Autism Dev Disord 34, 433-438.

19. Wakefield AJ, Anthony A \& Murch SH (2000) Enterocolitis in children with developmental disorders. Am J Gastroenterol 95, 2285-2295.

20. White JF (2003) Intestinal pathology in autism. Exp Biol Med (Maywood) 228, 639-649.

21. Berry D \& Hyppönen E (2011) Determinants of vitamin D status: focus on genetic variations. Curr Opin Nephrol Hypertens 20, 331336.

22. Cahill LE \& El-Sohemy A (2009) Vitamin C transporter gene polymorphisms, dietary vitamin $\mathrm{C}$ and serum ascorbic acid. $J$ Nutrigenet Nutrigenomics 2, 292-301.

23. Wei X, Xiujuan Z \& Shufen C (2007) Nutritional survey for serum levels of iodine, iron and zinc in school-age children of Harbin in 2004. Chin J Endemiol 26, 44-46.

24. Chinese Nutrition Society (2001) Chinese dietary reference intakes, DRIs. Acta Nutrimenta Sin 23, 193-196.

25. Miller KW \& Yang CS (1985) An isocratic high-performance liquid chromatography method for the simultaneous analysis of plasma retinol, alpha-tocopherol, and various carotenoids. Anal Biochem 145, 21-26.

26. de Onis M, Onyango AW, Van den Broeck J, et al. (2004) Measurement and standardization protocols for anthropometry used in the construction of a new international growth reference. Food Nutr Bull 25, S27-S36.

27. World Health Organization (2009) World Health Organization Anthro for Personal Computers, Version 3.01: Software for Assessing Growth and Development of the World's Children. Geneva: WHO.

28. World Health Organization (2008) Training Course on Child Growth Assessment WHO Child Growth Standards, p. 14. Geneva: WHO.

29. Bandini LG, Anderson SE, Curtin C, et al. (2010) Food selectivity in children with autism spectrum disorders and typically developing children. J Pediatr 157, 259-264.

30. Zimmer MH, Hart LC, Manning-Courtney P, et al. (2012) Food variety as a predictor of nutritional status among children with autism. J Autism Dev Disord 42, 549-556.

31. Horvath K, Papadimitriou JC, Rabsztyn A, et al. (1999) Gastrointestinal abnormalities in children with autistic disorder. J Pediatr 135, 559-563.

32. Quigley EM \& Hurley D (2000) Autism and the gastrointestinal tract. Am J Gastroenterol 95, 2154-2156.

33. Levy SE, Souders MC, Ittenbach RF, et al. (2007) Relationship of dietary intake to gastrointestinal symptoms in children with autistic spectrum disorders. Biol Psychiatry 61, 492-497.

34. Goday P (2008) Whey watchers and wheat watchers: the case against gluten and casein in autism. Nutr Clin Pract 23, 581-582.

35. Cornish E (2002) Gluten and casein free diets in autism: a study of the effects on food choice and nutrition. J Hum Nutr Diet 15, 261-269.

36. Yin SA \& Lai JQ (2008) Nutrition and Health State of 0-6 Years Chinese Cbildren, The Survey of Nutrition and Health State of Chinese Residents in 2002. Beijing: People's Medical Publishing House.

37. Cermak SA, Curtin C \& Bandini LG (2010) Food selectivity and sensory sensitivity in children with autism spectrum disorders. J Am Diet Assoc 110, 238-246.

38. Zhao LY, Yu DM, Liu AD, et al. (2008) Analysis of health selective survey result of children and pregnant/lying-in women in China in 2006. J Hyg Res 37, 65-67.

39. Shearer TR, Larson K, Neuschwander J, et al. (1982) Minerals in the hair and nutrient intake of autistic children. J Autism Dev Disord 12, 25-34.

40. Adams JB, Audhya T, McDonough-Means S, et al. (2011) Nutritional and metabolic status of children with autism vs. neurotypical children, and the association with autism severity. Nutr Metab 8, 34-66.

41. Ma G, Li Y, Jin Y, et al. (2007) Assessment of intake inadequacy and food sources of zinc of people in China. Public Health Nutr $10,848-554$.

42. Ali A, Waly MI, Al-Farsi YM, et al. (2011) Hyperhomocysteinemia among Omani autistic children: a case-control study. Acta Biochim Pol 58, 547-551.

43. James SJ, Cutler P, Melnyk S, et al. (2004) Metabolic biomarkers of increased oxidative stress and impaired methylation capacity in children with autism. Am J Clin Nutr 80, 1611-1617.

44. James SJ, Melnyk S, Fuchs G, et al. (2009) Efficacy of methylcobalamin and folinic acid treatment on glutathione redox status in children with autism. Am J Clin Nutr 89, 425-430.

45. Buie T, Campbell DB, Fuchs GJ, et al. (2010) Evaluation, diagnosis, and treatment of gastrointestinal disorders in individuals with ASDs: a consensus report. Pediatrics 125, S1-S18.

46. Falciglia GA, Horner SL, Liang J, et al. (2009) Assessing dietary variety in children: development and validation of a predictive equation. J Am Diet Assoc 109, 641-647. 